\title{
0 espaço das disciplinas na reconfiguração curricular do ensino médio brasileiro: 0 Enem e a História
}

\author{
Kleber Luiz Gavião Machado de Souza* \\ Maria Inês Sucupira Stamatto
}

\section{Resumo}

O objetivo deste texto é analisar o espaço ocupado pela disciplina de História nas matrizes de referência do Exame Nacional do Ensino Médio (Enem). A hipótese é de que, apesar de ser um exame interdisciplinar, existe um espaço claro para a disciplina no conjunto dos conhecimentos, competências e habilidades das Ciências Humanas e suas Tecnologias. Tal assertiva será verificada por meio da análise das três versões existentes da matriz do exame (1998, 2009 e 2011). As questões que norteiam este estudo são: qual é o espaço reservado à disciplina de História dentro dos conhecimentos, competências e habilidades das Ciências Humanas e suas Tecnologias? Se o Enem é um exame interdisciplinar, é possível encontrar referências claras ao conhecimento histórico dentro das outras áreas do conhecimento? As versões serão interpeladas pela leitura de documentos oficiais, orientadores do exame, para compararmos aspectos existentes nessa documentação em relação às matrizes de referência. A pertinência teórica desta proposta está centrada nas assertivas dos estudos relacionados às políticas educacionais que afirmam em seus textos, na forma de orientações, análises, relatórios e parâmetros, são suficientemente abertos para permitirem interpretações e reinterpretações que geram significados diversos.

Palavras-chave: Ensino de História. Políticas educacionais. Enem. Competências e habilidades. Interdisciplinaridade.

Recebido: 27/04/2014 - Aprovado: 29/06/2014

http://dx.doi.org/10.5335/rep.v21i2.4299

Doutorando em Educação pela Universidade Federal do Rio Grande do Norte (PPGED/UFRN). E-mail: kleberluiz.ufs@ gmail.com.

** Doutora em História pela Sorbonne, Paris III. Professora do Programa de Pós-Graduação da Universidade Federal do Rio Grande do Norte. E-mail: stamattoines@gmail.com. 


\section{Introdução}

Qual é o espaço ocupado pela História dentro das matrizes de referências do Enem em suas diferentes versões? Qual o espaço reservado à disciplina História dentro dos conhecimentos, das competências e das habilidades das Ciências Humanas e suas Tecnologias? Se o Enem é um exame interdisciplinar, é possível encontrar referências claras ao conhecimento histórico dentro das outras áreas do conhecimento?

Essas questões instigaram-nos a analisar as várias versões das matrizes de referências que estabeleceram o padrão de competências e habilidades para os alunos do ensino médio, testadas no Enem, avaliação referendada como interdisciplinar.

O Exame Nacional do Ensino Médio (Enem), segundo os relatórios pedagógi$\cos$ (2004 e 2005) lançados pelo Instituto Nacional de Estudos e Pesquisas Educacionais Anísio Teixeira (Inep), é definido como um

[...] exame individual, de caráter voluntário, oferecido anualmente aos concluintes e egressos do ensino médio, com o objetivo principal de possibilitar a todos os que dele participam uma referência para autoavaliação, a partir das competências e habilidades que estruturam o exame (INEP, 2007a, p. 27; 2007b, p. 7).

Enquanto política pública ${ }^{1}$ de avaliação da qualidade da educação brasileira, o exame faz parte de uma cultura de avaliação preocupada em aferir a eficiência do sistema de ensino brasileiro que, segundo alguns especialistas, já vinha construída desde a década de 1980 por meio de políticas pontuais (MINHOTO, 2008, p. $68 ; 2009$, p. 33). O certame é parte do Sistema Nacional de Avaliação (SNA) que contém outros instrumentos de avaliação nos diferentes níveis de ensino, e que teve as suas bases oficialmente lançadas com a Lei de Diretrizes e Bases da Educação Nacional (LDBEN), ${ }^{2}$ de 1996. Conforme o próprio texto indica no título IV que trata da Organização da educação nacional, uma das incumbências da União (art. 9º é a de:

V - coletar, analisar e disseminar informações sobre a educação; VI - assegurar processo nacional de avaliação do rendimento escolar no ensino fundamental, médio e superior, em colaboração com os sistemas de ensino, objetivando a definição de prioridades e a melhoria da qualidade do ensino (LDBEN, 1996, p. 29).

Enquanto forma curricular, o Enem pode ser enquadrado dentro do conceito de currículo avaliado proposto por Gimeno Sacristán (1998), visto que a avaliação continuada do currículo, materializada no modo de exames e provas, propostos por professores ou mesmo por instituições, é parte do seu processo de consolidação dentro de um sistema educacional, e cujo objetivo é ordenar "como deve ser a prática escolar, ainda que seja sob a forma de sugestões, avaliando essa prática do 
currículo através da inspeção ou por meio de uma avaliação externa dos alunos” (SACRISTÁN, 1998, p. 118).

Assim, como uma série de outras questões relacionadas aos elementos que compõem as reformas educacionais encabeçadas pelo Estado brasileiro, a partir de meados da década de 1990 (como legislação, parâmetros curriculares, gestão escolar, financiamento, expansão de vagas, etc.) a política de avaliação da educação também apresenta um debate polarizado. Para alguns autores, a exemplo de Castro (2009), o Enem é considerado

[...] um instrumento fundamental na prestação de contas à sociedade e de visualização da educação no Brasil e sobre o nível de aprendizado das competências e habilidades básicas propostas por um sistema de ensino, substituindo processos avaliativos de desempenho com base em indicadores de acesso, permanência, matrícula, cobertura, repetência, evasão, anos de estudo, etc (CASTRO, 2009, p. 7).

Para outros autores, o que consideramos majoritário na interpretação, o exame é visto como uma política avaliativa meritocrática, homogeneizante e ranqueadora do sistema educacional (OLIVEIRA, 2006, p. 78). Aponta-se a contradição entre o papel centralizador do Estado na elaboração e avaliação das políticas públicas, o que interfere, diretamente, na autonomia docente, e na postura descentralizadora da sua aplicação, delegando ao corpo escolar a responsabilidade na execução da avaliação (BERGAMIN, 2013, p. 147). Por meio dessa lógica,

[...] a avaliação ganha destaque e se converte em instrumento imprescindível às reformas educacionais, articulando-se aos demais aspectos da política educativa, visando não apenas a um maior controle do Estado no que se refere ao currículo e ao sistema escolar, mas também ao controle dos recursos destinados à educação. Em outras palavras, figura como instrumento de "gestão" dos sistemas educacionais (MINHOTO, 2009, p. 32).

Sob esse prisma, o Enem estaria não apenas avaliando os egressos do ensino médio, mas, também, tornando-se um instrumento nas políticas públicas na educação, consolidando a implementação de um novo currículo organizado por áreas de conhecimento.

\section{Enem: trajetória e características}

Em um brevíssimo histórico, o Enem é realizado desde 1998 e ganhou popularidade a partir de 2004, quando o Ministério da Educação (MEC) passou a conceder bolsas de estudo em instituições privadas por meio do Programa Universidade para Todos (Prouni), usando a nota obtida no exame como critério de seleção (CASTRO, 2009, p. 9). 
Durante os 12 primeiros anos de existência, funcionou de forma terceirizada, ou seja, todas as suas etapas de organização eram elaboradas e aplicadas por uma fundação privada, a Cesgranrio, que passou a executar desde a aplicação dos questionários socioeconômicos, passando pela criação de uma base de dados referente ao exame, até a implementação de uma metodologia própria para a correção das provas, a Teoria de Resposta ao Item (TRI). ${ }^{3}$ Tal quadro mudaria no ano de 2000 quando a Fundação Carlos Chagas (FCC) passa a dividir o trabalho com a Cesgranrio (MINHOTO, 2008, p. 74-75).

Em 2009, é instituído o novo Enem, que começa a utilizar as notas do exame para a admissão nas Instituições de Ensino Superior (IES) públicas no país. A partir do ano de 2010, a aplicação mudou das mãos do consórcio Carlos Chagas/ Cesgranrio para as do Instituto Nacional de Estudos e Pesquisas Educacionais Anísio Teixeira (Inep) do Ministério da Educação (MEC).

Do ponto de vista epistemológico, há três características específicas do exame que nos interessam em particular: a organização por áreas de conhecimento, a mediação desses por meio das competências e habilidades e a instrumentalização das duas anteriores pelas matrizes de referência. A estruturação por áreas de conhecimento segue uma das premissas básicas da reforma curricular que mudou a face do ensino médio nos últimos 15 anos. De acordo com as Diretrizes Curriculares Nacionais do Ensino Médio, a justificativa de tal organização é

[...] assegurar uma educação de base científica e tecnológica, na qual conceito, aplicação e solução de problemas concretos são combinados com uma revisão dos componentes socioculturais orientados por uma visão epistemológica que concilie humanismo e tecnologia ou humanismo numa sociedade tecnológica (BRASIL, 1998, p. 19).

A outra característica é a estruturação das áreas de conhecimento acerca de um conjunto de "qualificações gerais ou capacidades operativas articuladas" (INEP, 2007a, p. 31), as competências, que, por sua vez, são verificadas nas questões por meio de um conjunto de "capacidades operativas específicas", entendidas como habilidades "próprias ao jovem e jovem adulto, na fase de desenvolvimento cognitivo e social correspondente ao término da escolaridade básica" (INEP, 2007a, p. 31-32).

Por fim, tais competências e habilidades estão dispostas em uma matriz de conhecimentos que, segundo os relatórios pedagógicos do exame, tem como documentos norteadores a Lei de Diretrizes e Bases da Educação Nacional (LDB), os Parâmetros Curriculares Nacionais (PCN), as Diretrizes do Conselho Nacional de Educação sobre a Educação Básica e os textos da Reforma do Ensino Médio (INEP, 2007a, p. 32).

Como a compreensão das matrizes é essencial a este estudo, cabe-nos comentar mais detalhadamente. A matriz de conhecimentos do Enem tem três versões. A primeira, de 1998, constitui-se de um conjunto de cinco competências comuns a todas as áreas que se expressam em 21 habilidades. 
Na matriz de 2009, as competências e habilidades passam a ser estruturadas pelas áreas de conhecimento. Além disso, acontece a separação da disciplina Matemática do conjunto das Ciências da Natureza e sua autonomização em uma área específica. Já na matriz lançada em 2011, houve o acréscimo de competências e habilidades específicas para a avaliação da redação. Ainda assim, mantêm-se as cinco competências comuns, que não se alteram para os editais dos anos posteriores (INEP, 2012; 2013). Assim, temos:

I. Dominar linguagens $(D L)$ dominar a norma culta da Língua Portuguesa e fazer uso das linguagens matemática, artística e científica e das línguas espanhola e inglesa, ${ }^{4}$ II. Compreender fenômenos $(C F)$ construir e aplicar conceitos das várias áreas do conhecimento para a compreensão de fenômenos naturais, de processos geográficos, da produção tecnológica e das manifestações artísticas. III. Enfrentar situações-problema (SP) selecionar, organizar, relacionar, interpretar dados e informações representados de diferentes formas, para tomar decisões e enfrentar situações-problema. IV. Construir argumentação (CA) relacionar informações, representadas em formas, e conhecimentos disponíveis em situações concretas, para construir argumentação consistente. V. Elaborar propostas (EP) recorrer aos conhecimentos desenvolvidos na escola para elaboração de propostas de intervenção solidária na realidade, respeitando os valores humanos e considerando a diversidade sociocultural (INEP, 2009; p. 201, grifos do original).

As cinco competências existentes não dão possibilidade de separações disciplinares ou por áreas, visto que o objetivo dessas é perpassarem todas as áreas, mesmo que as próprias vozes que defendem a avaliação assumam ${ }^{5}$ que as Linguagens e Códigos e suas Tecnologias sejam privilegiadas em todas as competências, como afirma Zuleika de Felice Murrie (2005):

Com certeza a área se mostra na leitura presente na descrição de todas as competências. O grupo autor da matriz decidiu elegê-la como uma arquicompetência. Esse grupo, formado de professores de várias disciplinas, indicou que, sem o desenvolvimento pleno da atividade leitora, todas as competências e habilidades avaliáveis teriam suas possibilidades reduzidas ou interrompidas. Pela primeira vez, em situação de avaliação institucional, assume-se o papel essencial da leitura como pré-requisito básico (MURRIE, 2005, p. 57).

Tal posicionamento é reforçado em alguns dos relatórios pedagógicos do exame ao afirmarem que:

A Matriz de Competências pressupõe, ainda, que a competência de ler, compreender, interpretar e produzir textos, no sentido amplo do termo, não se desenvolve unicamente na aprendizagem da Língua Portuguesa, mas em todas as áreas e disciplinas que estruturam as atividades pedagógicas na escola. $\mathrm{O}$ participante deve, portanto, demonstrar, concomitantemente, possuir instrumental de comunicação e expressão adequado, tanto para a compreensão de um problema matemático quanto para a descrição de um processo físico, químico ou biológico e, mesmo, para a percepção das transformações de espaço/ tempo da história, da geografia e da literatura (INEP, 2007a, p. 34; 2007b, p. 37; 2009, p. 55). 
Porém, tal perspectiva de indivisibilidade das competências em conhecimentos disciplinares não se sustenta no exame das habilidades. Por que não? Defendemos a premissa de que mesmo organizado por áreas de conhecimento, o Enem está contido dentro de uma lógica disciplinar, o que nos autoriza a criar instrumentos metodológicos específicos para a análise da disciplina de História dentro do conjunto das Ciências Humanas e suas Tecnologias. Comecemos com a própria LDBEN-1996 que na Seção IV, relativa ao ensino médio, referenda a organização por disciplina:

Art. 35. O ensino médio, etapa final da educação básica, com duração mínima de três anos, terá como finalidades:

$[\ldots]$

IV - a compreensão dos fundamentos científico-tecnológicos dos processos produtivos, relacionando a teoria com a prática, no ensino de cada disciplina (grifo nosso).

O nosso embasamento em relação a essa questão foi construído também na leitura de alguns documentos que nortearam as reformas empreendidas no ensino médio brasileiro nos últimos anos. Como é salientado no texto dos PCNEM+:

As linguagens, as ciências e as humanidades continuam sendo disciplinares, mas é preciso desenvolver seus conhecimentos de forma a constituírem, a um só tempo, cultura geral e instrumento para a vida, ou seja, desenvolver, em conjunto, conhecimentos e competências. [...] Para quem possa temer que se estejam violando os limites disciplinares, quando estes se compõem de conhecimentos e competências, vale lembrar que as próprias formas de organização do conhecimento - as disciplinas - têm passado por contínuos rearranjos. Muitas disciplinas acadêmicas e muitos campos da cultura são resultados de processos de sistematização recentes de conhecimentos práticos ou teóricos, reunindo elementos que, em outras épocas, estavam dispersos em distintas especialidades (PCNEM+, 2002, p. 14-15).

Isso pode ser observado mais especificamente no papel atribuído pelos PCNEM às Ciências Humanas e suas Tecnologias, cujo objetivo é desenvolver por meio dos conhecimentos, das competências e das habilidades da área,

[...] consciências críticas e criativas, capazes de gerar respostas adequadas a problemas atuais e a situações novas. Dentre estes, destacam-se a extensão da cidadania, que implica o conhecimento, o uso e a produção histórica dos direitos e deveres do cidadão e o desenvolvimento da consciência cívica e social, que implica a consideração do outro em cada decisão e atitude de natureza pública ou particular (BRASIL, 2000, p. 21, grifo nosso).

Pelo grifo acima, é possível perceber o papel que da compreensão histórica na assimilação dos objetivos da área. Além disso, podemos depreender também que há certo descompasso em se tratando de como o Enem é definido dentro de seus próprios muros, o que não garante que a palavra "interdisciplinaridade" possa ser usada com segurança para definir o exame. Nos relatórios e documentos básicos que fornecem os fundamentos e explicações operacionais da prova, há menções ao 
caráter interdisciplinar da avaliação ao comentar-se a parte objetiva do exame (INEP, 2007a, p. 44; 2007b, p. 49; 2009, p. 64), a elaboração das questões baseada em situações-problema (2007a, p. 74; 2007b, p. 90; 2009, p. 145) e a análise pedagógica dos itens (INEP, 2005, p. 130).

Porém, na sua fundamentação teórico-metodológica (2005), Nilson José Machado põe em xeque o próprio estatuto interdisciplinar do exame, afirmando que este já estaria superado como possibilidade de organização dos conhecimentos no Enem.

$\mathrm{O}$ discurso da interdisciplinaridade surge como contraponto à "fragmentação crescente dos objetos do conhecimento nas diversas áreas" (MACHADO, 2007, p. 42) e à dificuldade de enquadrar determinados fenômenos escolares no âmbito de uma única disciplina, o que a tornaria "bandeira aglutinadora na busca de uma visão sintética, de uma reconstrução da unidade perdida, da interação e da complementaridade nas ações, envolvendo diferentes disciplinas” (p. 42). Tal fragmentação está baseada na herança cartesiana, em que o conhecimento é subdividido, encadeado logicamente e irradiado de um ponto de origem (p. 46). A interdisciplinaridade somente tem produzido "efeitos paliativos" devido ao equívoco em achar que essa se faz apenas pelo "mero incremento das relações entre as disciplinas, mantidos seus respectivos objetivos/objetos, e mantidas as relações determinadas pelo sistema que constituem" (MACHADO, 2007, p. 51).

$\mathrm{O}$ autor propõe uma maneira de organização dos conhecimentos na forma de uma rede de múltiplas relações, similar às redes informáticas, em que sua organização não dependa de um centro irradiador (acentrismo), esteja sempre em processo constante de atualização (metamorfose) no decorrer do tempo e que os conhecimentos possam estabelecer relações com várias disciplinas (heterogeneidade). A perspectiva defendida seria a transdisciplinaridade, visto que essa daria conta de organizar o trabalho escolar "em torno de objetivos que transcendam os limites e os objetos das diferentes disciplinas" e deslocar o "foco das atenções dos conteúdos disciplinares para os projetos das pessoas" (MACHADO, 2007, p. 52). Para tal,

[...] é necessário repensar-se a própria concepção de conhecimento, incrementando-se a importância da imagem do mesmo como uma rede de significações, em contraposição e complementação à imagem cartesiana do encadeamento, predominante no pensamento ocidental. Ao lado do acentrismo e da metamorfose, a heterogeneidade é uma característica das redes de significações que constitui um natural convite ao trabalho transdisciplinar (MACHADO, 2007, p. 53).

Para suprir tal objetivo, considerando o fato de que o exame avalia apenas a dimensão explícita do que é aprendido, é necessário trabalhar a contextuação, ou seja, o aproveitamento e a incorporação das relações vividas em seu contexto de origem, criando um elo de comunicação entre a bagagem cultural do aluno 
(conhecimento tácito) e as formas (explícitas ou explicitáveis) do conhecimento. Finaliza-se dizendo que "muito do que se busca por meio de rótulos como interdisciplinaridade, transdisciplinaridade, ou mesmo transversalidade atende pelo nome de contextuação" (MACHADO, 2007, p. 53). Logo, fica claro que a própria noção de interdisciplinaridade, utilizada pelo exame em alguns de seus documentos, parece não coadunar com o que um dos autores da matriz do exame defende como sistema adequado de relação entre os conhecimentos. Ao invés da interdisciplinaridade defende-se contextuação.

\section{As matrizes e a disciplina História}

Em virtude do exposto até o momento, defendemos que é possível fazer separações disciplinares dentro do conjunto da área das humanidades. Essas explicações devem ser feitas se levarmos em consideração a já conhecida crítica de que o formato por áreas de conhecimento contribui para a diluição dos conhecimentos das disciplinas e a perda do aprofundamento dos conceitos, das informações e dos métodos que as caracterizam.

E como será feita a escolha, dentro do quadro das Ciências Humanas e suas Tecnologias, das competências e habilidades em que o conhecimento histórico seja privilegiado? Seguimos as sentenças presentes na descrição de cada uma das seis áreas presentes nas Ciências Humanas e suas Tecnologias. As sentenças trazem locuções que indicam direcionamento histórico, como "interpretar historicamente", "identificar registros" e "compreender contextos históricos", entre outros. Levamos em consideração também a presença de competências e habilidades que trabalhem conceitos meta-históricos ${ }^{6}$ como memória, identidade, mudanças, permanências, rupturas, fonte e interpretação, entre outros.

Selecionamos ainda competências, habilidades e conceitos debatidos dentro da área do ensino de História e as políticas públicas para o ensino de cidadania, ética, protagonismo, direitos humanos, democracia, inclusão e exclusão social, políticas afirmativas, gênero, diversidade, relações étnico raciais, preconceito e racismo, entre outros.

Seria inviável reproduzirmos a lista de habilidades da primeira versão da matriz e as alterações existentes a partir da segunda versão da matriz, na qual são delimitadas capacidades operativas específicas para cada uma das áreas de conhecimento. O nosso foco é comparar, nas suas três versões, o espaço ocupado pela disciplina História dentro do quadro das Ciências Humanas e suas Tecnologias e como o conhecimento histórico é mobilizado dentro das demais áreas, verificando assim, o grau de interdisciplinaridade do Enem. 
Seguindo a ordem cronológica, ao investigarmos as matrizes de conhecimentos lançadas em 1998, podemos separar, no conjunto das 21 habilidades, quatro habilidades que podem ser consideradas como um bloco que contempla as Ciências Humanas e suas Tecnologias. Eis a seguir:

18. Valorizar a diversidade dos patrimônios etnoculturais e artísticos, identificando-a em suas manifestações e representações em diferentes sociedades, épocas e lugares.

19. Confrontar interpretações diversas de situações ou fatos de natureza histórico-geográfica, técnico-científica, artístico-cultural ou do cotidiano, comparando diferentes pontos de vista, identificando os pressupostos de cada interpretação e analisando a validade dos argumentos utilizados.

20. Comparar processos de formação socioeconômica, relacionando-os com seu contexto histórico e geográfico.

21. Dado um conjunto de informações sobre uma realidade histórico-geográfica, contextualizar e ordenar os eventos registrados, compreendendo a importância dos fatores sociais, econômicos, políticos ou culturais (INEP, 2007a, p. 34; 2007b, p. 37).

Interessante notar, a partir dos grifos que, apesar de ser um bloco de habilidades em que deveriam estar presentes todos os componentes disciplinares pertencentes às Humanidades (História, Geografia, Sociologia e Filosofia), os enunciados evidenciam o considerável peso da História, visto que nos quatro enunciados algum conceito-chave da História é requisitado, mais especificamente tempo (épocas, contexto, eventos e processos) e o binômio, fonte/interpretação (confrontar interpretações [...] comparando pontos de vista e processos, e ordenar eventos).

O conceito de tempo ainda aparece na habilidade dez, que, dentro do quadro das Ciências da Natureza, Matemática e suas Tecnologias requisita ao aluno "utilizar e interpretar diferentes escalas de tempo para situar e descrever transformações na atmosfera, biosfera, hidrosfera e litosfera, origem e evolução da vida, variações populacionais e modificações no espaço geográfico" (INEP, 2007, p. 33). Essas são as contribuições em que o conhecimento histórico aparece, explicitamente, dentro do conjunto das 21 habilidades que vigoraram na matriz de conhecimentos nas dez primeiras edições do exame, entre 1998 e 2008.

Já em 13 de maio de 2009 uma nova matriz de conhecimentos é aprovada pelo Comitê de Governança (formado pelo Ministério da Educação, Instituto Nacional de Pesquisas e Associação Nacional dos Dirigentes das Instituições Federais de Ensino Superior) e a partir dessa data, além das cinco competências básicas, cada área terá competências e habilidades específicas. Segundo o documento:

Estabelecida a Matriz de Referência, os objetos de conhecimento associados poderão ser aprimorados, nas edições seguintes do Enem, de modo a consagrar o papel do Exame de orientar a melhoria do ensino médio em harmonia com os processos de seleção para 0 acesso à Educação Superior (MEC, 2009, p. 1). 
Mas não é o que acontece nos anos seguintes, pois na matriz de 2011, excetuando-se as mudanças comentadas em trechos anteriores do texto, a mesma lista de competências e habilidades permanece e é replicada nos editais do exame dos anos posteriores (INEP, 2012, 2013). Em relação à área das Ciências Humanas e suas Tecnologias, essa matriz em nada difere das que subsidiaram os exames dos anos seguintes. Dos seis grupos de competências, excluímos por inteiro a área quatro, por ter sido a única a não fazer qualquer menção direta ou indireta aos conhecimentos da disciplina de História. Fizemos a seleção de 20 habilidades que contém algumas das especificidades da disciplina História no conjunto das trinta que compõem a área.

Quadro 1 -Competências e habilidades selecionadas na matriz de conhecimentos do Exame Nacional do Ensino Médio (Enem)

\begin{tabular}{|c|c|}
\hline Competências & Habilidades \\
\hline $\begin{array}{l}\text { Área } 1 \text { - compreender os ele- } \\
\text { mentos culturais que constituem } \\
\text { as identidades. }\end{array}$ & $\begin{array}{l}\text { H1 - interpretar historica e/ou geograficamente fontes documentais acerca } \\
\text { de aspectos da cultura. } \\
\text { H2 - analisar a produção da memória pelas sociedades humanas. } \\
\text { H3 - associar as manifestações culturais do presente aos seus processos } \\
\text { históricos. } \\
\text { H4 - comparar pontos de vista expressos em diferentes fontes sobre deter- } \\
\text { minado aspecto da cultura. }\end{array}$ \\
\hline $\begin{array}{l}\text { Área } 2 \text { - compreender as trans- } \\
\text { formações dos espaços geográ- } \\
\text { ficos como produto das relações } \\
\text { socioeconômicas e culturais de } \\
\text { poder. }\end{array}$ & $\begin{array}{l}\text { H7 - identificar os significados histórico-geográficos das relações de poder } \\
\text { entre as nações. } \\
\text { H9 - comparar o significado histórico-geográfico das organizações políticas } \\
\text { e socioeconômicas em escala local, regional ou mundial. } \\
\text { H10 - reconhecer a dinâmica da organização dos movimentos sociais e a } \\
\text { importância da participação da coletividade na transformação da realidade } \\
\text { histórico-geográfica. }\end{array}$ \\
\hline $\begin{array}{l}\text { Área } 3 \text { - compreender a pro- } \\
\text { dução e o papel histórico das } \\
\text { instituições sociais, políticas e } \\
\text { econômicas, associando-as aos } \\
\text { diferentes grupos, conflitos e } \\
\text { movimentos sociais. }\end{array}$ & $\begin{array}{l}\text { H11 - identificar registros de práticas de grupos sociais no tempo e no espaço. } \\
\text { H12 - analisar o papel da justiça como instituição na organização das } \\
\text { sociedades. } \\
\text { H13 - analisar a atuação dos movimentos sociais que contribuíram para } \\
\text { mudanças ou rupturas em processos de disputa pelo poder. } \\
\text { H14 - comparar diferentes pontos de vista, presentes em textos analíticos } \\
\text { e interpretativos, sobre situação ou fatos de natureza histórico-geográfica } \\
\text { acerca das instituições sociais, políticas e econômicas. } \\
\text { H15 - avaliar criticamente conflitos culturais, sociais, políticos, econômicos } \\
\text { ou ambientais ao longo da história. }\end{array}$ \\
\hline $\begin{array}{l}\text { Área } 5 \text { - utilizar os conhecimen- } \\
\text { tos históricos para compreender } \\
\text { e valorizar os fundamentos da } \\
\text { cidadania e da democracia, fa- } \\
\text { vorecendo uma atuação consci- } \\
\text { ente do indivíduo na sociedade. }\end{array}$ & $\begin{array}{l}\text { H21 - identificar o papel dos meios de comunicação na construção da vida social. } \\
\text { H22 - analisar as lutas sociais e conquistas obtidas no que se refere às } \\
\text { mudanças nas legislações ou nas políticas públicas. } \\
\text { H23 - analisar a importância dos valores éticos na estruturação política das } \\
\text { sociedades. } \\
\text { H24 - relacionar cidadania e democracia na organização das sociedades. } \\
\text { H25 - identificar estratégias que promovam formas de inclusão social; }\end{array}$ \\
\hline $\begin{array}{l}\text { Área } 6 \text { - compreender a socie- } \\
\text { dade e a natureza, reconhecen- } \\
\text { do suas interações no espaço } \\
\text { em diferentes contextos históri- } \\
\text { cos e geográficos. }\end{array}$ & $\begin{array}{l}\text { H26 - identificar em fontes diversas o processo de ocupação dos meios } \\
\text { físicos e as relações da vida humana com a paisagem. } \\
\text { H27 - analisar de maneira crítica as interações da sociedade com o meio } \\
\text { físico, levando em consideração aspectos históricos e(ou) geográficos. } \\
\text { H28 - relacionar o uso das tecnologias com os impactos socioambientais } \\
\text { em diferentes contextos histórico-geográficos. }\end{array}$ \\
\hline
\end{tabular}


O que o quadro e os elementos que grifamos nos indicam? Em primeiro lugar, dos cinco grupos de áreas selecionados, quatro desses fazem referência ao uso do conhecimento histórico, seja por meio do trabalho com o conceito de identidade (CA1) ou sob rótulos como "papel/conhecimentos/contextos históricos" (CA3, CA5 e CA6).

É possível perceber também a tese, bastante clara nos enunciados, seja das competências como das habilidades, que a dimensão temporal do conhecimento histórico não pode ser dissociada da dimensão espacial, ou seja, os conceitos de tempo e espaço parecem ser indissociáveis na matriz, o que remeteria a uma estreita ligação com a Geografia. Nas habilidades, o par "histórico-geográfico" é bastante trabalhado (H1, H7, H9, H10, H11, H14 e H27). O tempo é aprimorado na análise dos "contextos" (CA6), "processos" (H3) e das "mudanças e "rupturas" (H13). Outro aspecto também é o exercício de interpretação (H1), análise (H2), comparação (H4 e H14) e identificação (H11 e H26) das diferentes fontes, registros e pontos de vista no transcorrer das habilidades.

A competência de área cinco utiliza os conhecimentos históricos para trabalhar competências, habilidades e conceitos debatidos na área do ensino de História e pelas políticas públicas para o ensino, como cidadania, ética, protagonismo, democracia, inclusão social e políticas públicas, entre outros.

Seria limitado procurar os conhecimentos da disciplina de História apenas nas Ciências Humanas e suas Tecnologias, por isso procuramos o conhecimento histórico também nas competências e habilidades das outras áreas. $\mathrm{O}$ resultado não é animador.

Se as palavras/expressões interdisciplinaridade, rede de conhecimentos, transdisciplinaridade e mesmo a concepção a respeito da importância do estudo da disciplina História como essencial para a compreensão da heterogeneidade das relações entre os conhecimentos ao longo do tempo são anunciadas no documento, não ficam expressas nas outras áreas do conhecimento, como podemos observar na análise das matrizes.

Na matriz das Linguagens, Códigos e suas Tecnologias, no conjunto de suas nove áreas e trinta habilidades, apenas duas capacidades específicas, cada uma em competência diferente, abordam os conhecimentos da História. Assim, temos:

- Competência de área 5 - Analisar, interpretar e aplicar recursos expressivos das linguagens, relacionando textos com seus contextos, mediante a natureza, função, organização, estrutura das manifestações, de acordo com as condições de produção e recepção.

$H 15$ - Estabelecer relações entre o texto literário e o momento de sua produção, situando aspectos do contexto histórico, social e político. 
- Competência de área 6 - Compreender e usar os sistemas simbólicos das diferentes linguagens como meios de organização cognitiva da realidade pela constituição de significados, expressão, comunicação e informação.

H2O - Reconhecer a importância do patrimônio linguístico para a preservação da memória e da identidade nacional.

Mais uma vez a referência genérica do contexto histórico é acionada como vertente de interpretação do tempo histórico nas outras áreas do exame, apesar de toda a diversidade de pesquisas relacionadas aos conceitos considerados elementares para o ensino de História. A memória também não é problematizada e nem a diversidade de significados que um conceito como identidade nacional pode alcançar.

$\mathrm{Na}$ matriz de referência da Matemática e suas Tecnologias não encontramos nenhuma menção a qualquer conceito, competência ou habilidade que integre à área ao estudo da História, de forma direta ou indireta, no conjunto de suas seis áreas e trinta habilidades, o que soa estranho, visto que a própria fundamentação teórica e metodológica do exame salienta a importância do estudo da História em diferentes disciplinas.

Segundo Nilson José Machado, a constante atualização das relações fundadoras de certas disciplinas e conhecimentos justifica a presença constante do estudo da disciplina História, visto que a "metamorfose, como uma característica das redes de significações, constitui um argumento decisivo para destacar a importância da História para o ensino de qualquer tema, tanto a História em sentido pleno quanto à história da disciplina que se pretende ensinar" (MACHADO, 2005, p. 48).

Nas Ciências da Natureza e suas Tecnologias, apenas uma:

- Competência de área 1 - Compreender as ciências naturais e as tecnologias a elas associadas como construções humanas, percebendo seus papéis nos processos de produção e no desenvolvimento econômico e social da humanidade. $H 3$ - Confrontar interpretações científicas com interpretações baseadas no senso comum, ao longo do tempo ou em diferentes culturas.

Essa habilidade foi a mais próxima de uma perspectiva histórica a ser trabalhada no conjunto dos conhecimentos disciplinares das Ciências da Natureza. Tal panorama frustra, em parte, as expectativas de inter-relação entre as áreas, visto que, ao serem aprovadas as matrizes de 2009, o Comitê de Governança que as valida deixa claro que:

Por recomendação da reunião, a partir da edição de 2010, os conhecimentos de Física, Química e Biologia, associados à matriz de referência de Ciências da Natureza e suas Tecnologias, devem expressar integração crescente entre as três áreas, adequando-se à perspectiva interdisciplinar das competências e habilidades adotadas na matriz de referência correspondente (MEC, 2009, p. 1). 
Dessa forma, ao menos em termos de conceitos básicos explícitos, a integração entre as três áreas é tênue. Falta-nos um estudo da possibilidade de realizar a interdisciplinaridade por meio do desenvolvimento das competências e habilidades selecionadas na matriz de referência das áreas. Nesse sentido, o que fizemos foi selecionar indícios que propõem a discussão referente ao grau de diluição entre as disciplinas que compõem as Ciências Humanas e as possibilidades de integração entre as áreas não pelos conteúdos disciplinares, mas pelas competências cognitivas utilizadas no processo de seu conhecimento.

\section{Considerações finais}

A investigação comparada das matrizes de conhecimentos do Enem, buscando saber o espaço ocupado pela História, mostrou que, nas três versões existentes do documento, há um espaço disciplinar evidente para os conhecimentos da disciplina. Tanto na matriz de 1998 (uma lista de habilidades), como nas versões de 2009 e de 2011 (organizadas por áreas), as competências e habilidades trabalham, em sua grande maioria em prol do reforço de conteúdos conceituais tipicamente trabalhados pela pesquisa e ensino de História, como tempo, fonte, interpretação, memória, rupturas e mudança. Na matriz das humanidades, há também a historicização de conceitos ligados à prática da ética e da cidadania, por meio de uma competência de área específica.

Outro ponto são os indícios que apontam para uma proposital conjunção entre a História e a Geografia, como forma de mostrar que todos os fenômenos que orbitam nas humanidades, devem ser interpretados à luz de tempos e espaços específicos. Apenas uma análise mais minuciosa pode esmiuçar o grau de convergências entre as duas disciplinas.

Nas demais áreas, os conhecimentos da disciplina História, praticamente desaparecem no conjunto das outras três áreas que compõem o exame, cada uma com uma média de trinta habilidades cada, o que mostra uma grande lacuna na proposta do exame de inter-relacionar, transversalizar ou mesmo contextuar os conhecimentos entre as diferentes áreas. Independentemente da palavra utilizada, olhando pelo ângulo da História, há um hiato na proposta explicitada nos documentos oficiais do exame. 


\title{
Space of disciplines in the curricular reconfiguration of brazilian second grade: Enem and History
}

\begin{abstract}
The objective of this text is to analyze the space occupied by history discipline in the matrizes de referência do Exame Nacional do Ensino Médio exam (Enem). Our hypothesis is that, although it is an interdisciplinary exam, there is a clear space for this discipline in the set of knowledge, competences and abilities of Human Sciences and their Technologies. This assertive will be verified through the analysis of the three existing versions of the exam's matrixes (1998, 2009 and 2011). The guiding questions of this study are: what is the reserved space for the History discipline inside the knowledge, competences and abilities of Human Sciences and their Technologies? If Enem is an interdisciplinary exam, is it possible to find clear references of historical knowledge inside others knowledge areas? The versions will be interpreted by reading official knowledge-orienting documents of the exam to compare existing aspects of those documents in relation to the references matrixes. The theoretical pertinence of this proposal is centered in educational politics studies that claim their texts - in the form of orientations, analyses, reports and parameters - are open enough to allow interpretations and reinterpretations that generate diverse meanings.
\end{abstract}

Keywords: History teaching. Educational politics. Enem. Competences and abilities. Interdiciplinarity.

\section{Notas}

1 De acordo com Eloísa de Mattos Hofling (2001), as políticas públicas podem ser definidas como o "Estado em ação [...] implantando um projeto de governo, através de programas, de ações voltadas para setores específicos da sociedade". Para a autora, a educação seria uma política pública social, pois alia a responsabilidade do Estado "quanto à implementação e manutenção a partir de um processo de tomada de decisões que envolve órgãos públicos e diferentes organismos e agentes da sociedade relacionados à política implementada" e a proteção social para a "redistribuição dos benefícios sociais visando a diminuição das desigualdades estruturais produzidas pelo desenvolvimento socioeconômico". Assim, tais políticas são "formas de interferência do Estado, visando à manutenção das relações sociais de determinada formação social" (HOFLING, 2001, p. 31).

2 Lei n. 9.394, de 20 de dezembro de 1996.

3 A Teoria da Resposta ao Item (TRI) é uma metodologia que "sugere formas de representar a relação entre a probabilidade de um indivíduo dar uma certa resposta a um item e seus traços latentes. [...] A TRI é uma poderosa ferramenta estatística que surgiu para suprir as necessidades decorrentes das limitações da Teoria Clássica da Medida (TCM) [...]. Na TRI, os itens do teste são avaliados conjuntamente, enquanto que na TCM cada item equivale a uma pontuação independente de outro. A TRI consegue captar aqueles candidatos que "chutam" mais, penalizando a nota desse. [...] Assim, é possível que candidatos com mais itens acertados possam ter uma nota inferior a outros candidatos com menos itens acertados" (ANDRADE, TAVARES e VALLE, 2000, apud MOREIRA JUNIOR, 2010, p. 137-138).

4 Acrescidas ao exame a partir de 2010, conforme a segunda versão da Matriz.

5 Em 2005, o Inep lança Exame Nacional do Ensino Médio (ENEM): fundamentação teórico-metodológica, uma coletânea de textos elaborados pelos autores das Matrizes, com o objetivo de explicitar a concepção teórico-metodológica do exame. Discute-se a organização por áreas (com um texto específico que descrevem seus objetivos), as competências e habilidades, situações problemas, interdisciplinaridade, metodologia de correção do exame, etc. É uma coletânea de grande valor para sondar aspectos do exame que muitas vezes não ficam claros na leitura de outros documentos.

6 Os conceitos meta-históricos são responsáveis pela compreensão do trabalho do historiador e da ciência da História. Esses conceitos, geralmente, aparecem nas unidades iniciais dos livros e compõem uma espécie de vocabulário especializado (LEE, 2006, p. 136) que ajudaria na formação de uma consciência histórica avançada (BARCA, 2006, p. 108). São exemplos os conceitos de História, tempo (seus demarcadores - século, era, idade...), fonte, sujeito histórico, historicidade, interpretação, passado e mudança, (grifos do autor) entre outros (BARCA, 2006; COOPER, 2000, 2006; LEE, 2002). 


\section{Referências}

BALL, Stephen J. Sociologia das políticas educacionais e pesquisa crítico-social: uma revisão pessoal das políticas educacionais e da pesquisa em política educacional. In: BALL, Stephen J.; MAINARDES, Jefferson (Orgs.). Políticas educacionais: questões e dilemas. São Paulo: Cortez, 2011. p 21-53.

BRASIL, Mistério da Educação. Parâmetros curriculares nacionais para o ensino médio. Brasília: SEMTEC, 1999.

. Parâmetros curriculares nacionais para o ensino médio PCN+ Orientações Educacionais Complementares aos Parâmetros Curriculares Nacionais - Ciências Humanas e suas Tecnologias. Brasília: SEMTEC, 2002.

. Lei de Diretrizes e Bases da Educação Nacional n. 9.394/96.

Diretrizes Curriculares Nacionais para o ensino médio. Parecer CNE n. 15/98 - CEB. Aprovado em 1ํ de junho de 1998.

. Matriz de Referência para o ENEM. Brasília: MEC/INEP, 2009.

Matriz de Referência para o ENEM. Brasília: MEC/INEP, 2011.

BERGAMIN, Fabíola Matte Bergamin. Currículo e Exame Nacional do Ensino Médio: rupturas e permanências na conformação dos saberes históricos escolares. 2013. Dissertação (Mestrado em Educação) - Pontifícia Universidade Católica de São Paulo (PUC-SP), São Paulo, 2013.

CASTRO, Maria Helena Guimarães de. Sistemas de avaliação da educação no Brasil: avanços e novos desafios. São Paulo Perspectiva, São Paulo, v. 23, n. 1, p. 5-18, jan./jun. 2009.

HOFLING, ELOISA DE MATTOS. Estado e políticas (públicas) sociais. Cad. CEDES [online], v. 21, n. 55, p. 30-41, nov. 2001. Disponível em: <http://www.scielo.br/scielo.php?pid=S0101-32622001000300003\&script=sci_abstract\&tlng=pt>. Acesso em: 24 jul. 2013.

INSTITUTO NACIONAL DE ESTUDOS E PESQUISAS EDUCACIONAIS ANÍSIO TEIXEIRA. Exame Nacional do Ensino Médio (ENEM): Relatório Pedagógico 2004. Brasília: MEC/INEP, 2007a.

INEP, 2007b.

Exame Nacional do Ensino Médio (ENEM): Relatório pedagógico 2005. Brasília: MEC/ INEP, 2009.

. Exame Nacional do Ensino Médio (ENEM): Relatório pedagógico 2008. Brasília: MEC/ . ENEM: documento básico. Brasília, 2002.

. Edital n. 3, de 24 de maio de 2012: Exame Nacional do Ensino Médio (ENEM). Brasília: MEC/ INEP, 2012.

. Edital n. 1, de 8 de maio de 2013: Exame Nacional do Ensino Médio (ENEM). Brasília: MEC/ INEP, 2012.

SACRISTÁN, J Giméno. O currículo: uma reflexão sobre a prática. Porto Alegre: ArtMed, 1998. 
MACHADO, Nilson José. Interdisciplinaridade e contextuação. In: Instituto Nacional de Estudos e Pesquisas Educacionais Anísio Teixeira. Exame Nacional do Ensino Médio (ENEM): fundamentação teórico-metodológica. Brasília, 2005. p. 41-53.

MINHOTO, Maria Angélica Pedra. Da disseminação da cultura de avaliação educacional: estudo sobre a institucionalização do ENEM. Rev Poiésis, Tubarão, n. 1, v. 1, p. 67-85, jan./abr. 2008.

. Modelação curricular do ensino médio: análise de prescrições legais e do papel da avaliação dos sistemas de ensino. Jornal de políticas educacionais, n. 5, p. 27-36, jan./jun. 2009.

MOREIRA JUNIOR, Fernando de Jesus. Aplicações da Teoria da Resposta ao Item (TRI) no Brasil. Rev. Bras. Biom., São Paulo, v. 28, n. 1674, p. 137-170, 2010.

MURRIE, Zuleika de Felice. A área de Linguagens e Códigos e suas Tecnologias no ENEM. In: Instituto Nacional de Estudos e Pesquisas Educacionais Anísio Teixeira. Exame Nacional do Ensino Médio (ENEM): fundamentação teórico-metodológica. Brasília, 2005. p. 57-60.

OLIVEIRA, Zeli Alvim de. Saberes e práticas avaliativas no ensino de História: o impacto dos processos seletivos (PAIES e vestibular/UFU) e do ENEM na avaliação da aprendizagem no ensino médio, 2006, $137 f$. 